\title{
Videojuegos y convergencia creativa: de las redes sociales a las plataformas de libre creación
}

\author{
Video games and creative convergence: from social networks \\ to free creation platforms
}

\author{
José Enrique Ocaña Romero, Universidad de Málaga, (España) \\ Facultad de Ciencias de la Comunicación C/León Tolstoi, s/n, 29010 \\ Josenriqueor1987@gmail.es | Orcid: https://orcid.org/0000-0002-0934-8981
}

DOI: http://dx.doi.org/10.12795/Ambitos.2019.i45.12

\begin{abstract}
Resumen
La difusión de Internet y el uso masivo de las redes sociales ofrecen un panorama en el que la mayoría de medios culturales y artísticos como el cine, la literatura, la música o más recientemente los videojuegos, se han visto forzados a cambiar sus paradigmas internos. Se pasa de un modelo comunicativo vertical a uno horizontal, en el cual el usuario/consumidor pasivo se convierte en agente activo y en co-creador de sus propios contenidos, los cuales se exponen de manera masiva en las redes y en las plataformas de libre creación. A partir de los estudios que profundizan en el concepto primigenio de cultura participativa de Henry Jenkins, la presente investigación aborda el análisis de los modelos comunicativos en el videojuego y su constante evolución dentro de los entornos colaborativos digitales. Se ofrece además una exploración de la situación actual de los videojuegos como parte de una convergencia digital en constante ramificación y de total permeabilidad a las prácticas creativas del usuario que ayudan a expandir el universo del juego más allá de la pantalla. Partiendo del estudio cualitativo de la bibliografía aportada y mediante el examen de casos ejemplares de redes sociales de videojuegos como el de Assassin's Creed Council o el del videojuego independiente Blasphemous financiado a través de la plataforma
\end{abstract}


Kickstarter, se pretende demostrar que los modelos de producción de videojuegos o de cualquier obra de carácter cultural han cambiado notablemente, forzando a las empresas a seguir la estela de los patrones creativos marcados por el usuario/creador.

\begin{abstract}
The diffusion of the Internet and the massive use of social networks offer a panorama in which the majority of cultural media such as cinema or, more recently, videogames, have been forced to change their internal paradigms. It goes from a vertical communicative model to a horizontal one, in which the passive user / consumer becomes an active agent and co-creator of their own content, which is exposed in a massive way in the networks. From the studies that deepen in the primitive concept of participative culture of Henry Jenkins, the present investigation approaches the analysis of the communicative models in the video game and its constant evolution within the digital collaborative environments. It also offers an exploration of the current situation of video games as part of a digital convergence in constant branching and total permeability to the user's creative practices that help to expand the game universe beyond the screen. Starting from the qualitative study of the contributed bibliography and through the examination of exemplary cases of social networks like the one of Assassin's Creed Council or the one of the independent video game Blasphemous financed through the platform Kickstarter, it is tried to demonstrate that the models of production of games or of any work of a cultural nature have changed markedly, forcing companies to follow the trail of creative patterns marked by the user / creator.
\end{abstract}

Palabras Clave: cultura participativa, videojuegos, redes sociales, internet, creaciones artísticas.

Keywords: participatory culture, video games, social networks, internet, artistic creations.

\title{
1. INTRODUCCIÓN Y JUSTIFICACIÓN DEL TEMA
}

\subsection{Videojuegos: hacia un modelo de negocio transversal}

El uso masivo de Internet y las herramientas digitales obligó a la mayoría de medios de expresión cultural y artística como el cine, la literatura, la fotografía, la música y más recientemente los videojuegos, a cambiar sus paradigmas así como su estructura interna. Esto se debe, en parte, al potencial publicitario de Internet y a su uso como herramienta de difusión masiva de todo tipo de eventos relacionados con nuestra cultura y estilo de vida. 
Algunos de los factores que fomentan y aceleran la inclusión de estas herramientas digitales en los modelos de producción y consumo cultural son su transversalidad y horizontalidad, un modelo que difumina el rígido sistema vertical que se venía dando entre los productores de contenido y los consumidores pasivos antes de la explosión de las redes sociales y la web 2.0 .

Este modelo horizontal permite que quienes eran antes consumidores pasivos tengan la posibilidad de convertirse en co-creadores, en agentes activos en la elaboración de contenidos de toda índole creativa en mayor o menor grado de participación. Actualmente se está observando este cambio en el campo creativo de los videojuegos que, "como medio plantea una ruptura, parcial al menos, con las nociones tradicionales de autoría, producción y consumo" (Muriel, 2016, p. 1).

Desde el estudio del "fenómeno fan" hasta el concepto de cultura participativa, ambos términos de Henry Jenkins, se han realizado múltiples investigaciones sobre los entornos de colaboración en ecosistemas digitales y la evolución de estos como fenómenos sociales y comunicativos a través de ejemplos extraídos de la cultura televisiva, Internet y, más tarde, las redes sociales y las plataformas digitales de crowdfunding.

En esta investigación se ofrece una exploración de la situación actual de los videojuegos como parte de una cultura participativa en progresivo crecimiento y constante evolución. El estudio se centra en el potencial artístico del medio "videojuegos" tratando de forma accesoria las investigaciones sobre cultura participativa en otros ámbitos académicos como pueden ser la pedagogía, la psicología, la sociología o la antropología.

\subsection{Objetivos, hipótesis y metodología}

Las redes sociales hechas por y para fans de videojuegos exclusivamente y las plataformas digitales de patrocinio cambian por completo la relación tradicional entre autor - consumidor lo que "sitúa al videojuego en una situación privilegiada desde un punto de vista social, cultural y tecnológico" (Muriel, 2016, p. 10).

En un contexto en el que los entornos digitales participativos evolucionan constantemente, este trabajo pretende demostrar que el modelo de producción de videojuegos y otras obras de valor cultural y artístico gana transversalidad debido a que los usuarios se convierten en consumidores activos y en creadores de contenido artístico de calidad a través de las redes sociales de videojuegos y de las plataformas de libre creación, forzando así a las empresas y a los productores a buscar otras 
modalidades de negocio que se adapten a los patrones marcados por estas nuevas comunidades. Para ello, se persiguieron algunos objetivos fundamentales:

- El objetivo central del estudio es investigar la evolución del concepto de cultura participativa en los videojuegos a través del uso de las redes sociales y las plataformas de creación de contenido artístico y creativo relacionado con la cultura del videojuego.

- Realizar un repaso teórico y descriptivo de la bibliografía seleccionada en un intento por resaltar los conceptos más relevantes sobre la cultura participativa en relación con los videojuegos y los entornos digitales de colaboración.

- Identificar y analizar de forma breve y concisa algunos casos paradigmáticos de redes sociales exclusivas de videojuegos como Assassin's Creed Council o el videojuego independiente Blasphemous, patrocinado a través de Kickstarter, en un intento por definir la importancia y el impacto de este tipo de producciones y sus prácticas asociadas.

Se utiliza una metodología de tipo cualitativo que supone una recolección de artículos y documentos que recogen temas de referencia en el ámbito de estudio. Por otra parte y para ejemplificar lo que se propone en la investigación, se toman como referentes principales los casos del párrafo anterior y se analizan de manera breve debido a su carácter representativo. Las inferencias sustraídas arrojan luz sobre el objetivo de la investigación ayudando a desgranar el conjunto de posibilidades artísticas que ofrecen los entornos digitales de colaboración y sus contingencias actuales y futuras.

Existen algunos trabajos relevantes sobre redes sociales y videojuegos que hablan de su uso educativo, pero en el ámbito español son pocos los estudios que profundizan en este terreno a través del inicial concepto de Jenkins para ofrecer una visión actualizada desde el punto de vista de la creación artística inmersa en los entornos colaborativos digitales.

\section{MARCO TEÓRICO Y PLANTEAMIENTO DEL PROBLEMA}

\subsection{De la televisión a Internet: la expansión del fenómeno fan}

Previo a la eclosión de Internet y las redes sociales, en su obra Textual Poachers, televisión fans and participatory culture de 1992, Jenkins cimenta las bases de los estudios sobre el fenómeno fan y la cultura televisiva. En este estudio, el autor analiza el comportamiento y lo que hacen los fans con respecto a los contenidos mediáticos. 
Estos, entran en conflicto con las estructuras tradicionales pero agregando valor a dichos contenidos: "The history of media fandom is a least in part the history of a series of organized efforts to influence programing decisions" (Jenkins, 1992, p. 28).

No es hasta el año 2009 cuando el autor toma por primera vez como objeto de estudio central el concepto de cultura participativa en su obra como coautor Confronting the Challengues of Participatory Culture: Media Education for the 21st Century.

A participatory culture is a culture with relatively low barriers to artistic expression and civic engagement, strong support for creating and sharing one's creations, and some type of informal mentorship whereby what is known by the most experienced is passed along to novices (...) is also one in which members believe their contributions matter, and feel some degree of social connection with one another. (Jenkins, Clinton, Purushotma, Robinson y Weigel, 2009, p. 3)

En esta obra realizada por encargo de la fundación MacArthur, Henry Jenkins aborda una nueva cultura mediática a través del estudio de las novedosas formas de participación.

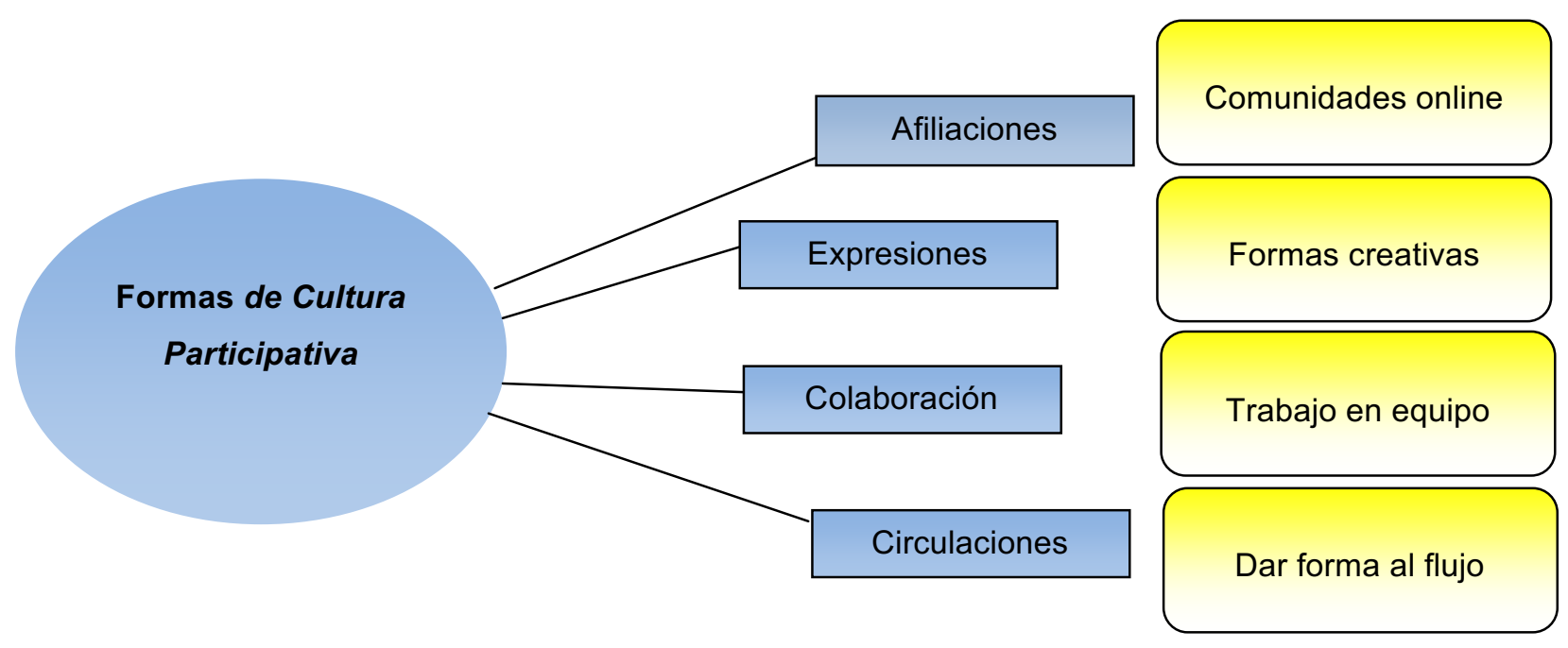

Figura 1. Formas y esferas de la cultura participativa según Jenkins

Fuente: elaboración propia basada en Jenkins et al, 2009, p. 3. 
Con el nacimiento de la plataforma de almacenamiento y difusión masiva Youtube y su lema Broadcast yourself, como si de un vaticinio se tratase, los fans de videojuegos adquieren una notable influencia debido a que empiezan a desenterrar un discurso personal y su visión sobre temas variados para llevarlo a las masas, lo que tiene como consecuencia un cambio de posición del fan activo o creador ante los demás miembros de la comunidad de seguidores. Una de las obras pioneras en tratar el tema de Youtube como plataforma altamente favorecida ante la cultura participativa es: Youtube: Digital Media and Society Series de Burguess y Green también publicada en el año 2009.

Las críticas a los conceptos ideados por Jenkins no tardaron en llegar. Nick Couldry reprende a Jenkins diciendo que el autor sólo se preocupa por analizar lo que hacen los fans dando por sentado que todos participan de la misma forma y con el mismo nivel de recursos. Couldry también argumenta que Jenkins olvida las relaciones de poder y que la participación de cada individuo está mediada por elementos culturales y sociales que hacen que esta convergencia no sea tan igualitaria: "the term convergence culture blurs important processes of differentiation and stratification and so blocks a better understanding of the politics of convergence" (Couldry, 2011, p. 1).

Un enfoque limitado que autores como Catherine Driscoll, Julie Wilson o Toby Miller, entre otros, se encargaron de señalar siguiendo las teorías de Couldry. Sin embargo, Jenkins trata de contestar con argumentos y de defender su posición ante estas críticas en artículos posteriores. A pesar de ello, los puntos señalados por Couldry y compañía se alzan como las limitaciones más obvias de este tipo de estudios culturales.

Por tanto, las limitaciones más graves del presente estudio están en la falta de recursos de una gran parte de la población mundial que, a día de hoy, no tienen la posibilidad de una conexión a Internet ni recursos tecnológicos suficientes. Un claro ejemplo de las limitaciones metodológicas que albergan este tipo de investigaciones por los factores nombrados anteriormente sería la tesis doctoral de Manzur (2017) en la que se tiene "como objeto de estudio analizar las prácticas culturales de los jugadores presentes en entornos comunicativos emergentes del juego social Candy Crush, centrándose en las redes sociales y las comunidades de jugadores de juegos digitales" (p. 1). 


\subsection{Las consecuencias positivas y negativas del fanfiction: del cine a los videojuegos independientes}

Algunos ejemplos relevantes de los efectos de la convergencia digital se pueden observar en las relaciones establecidas entre autores y grupos de fans a través de Internet y las redes sociales. J.K Rowling, autora de la exitosa saga literaria Harry Potter, siempre ha tenido una relación complicada con sus fans. Esto es así debido a que cuando Rowling publicó el último libro de su saga, los fans comenzaron a crear historias paralelas (fanfic) y la autora se pronunció al respecto diciendo que no tomaría acciones legales si esas obras se creaban sin ánimo de lucro.

Más tarde, Rowling crearía una saga cinematográfica nueva ambientada en el universo de sus libros anteriores, Animales fantásticos y dónde encontrarlos (20162019) "recurriendo a una acción persistente, y a la aparición constante de personajes a los que no les importa desafiar la cronología oficial (...) Rowling ya empieza a pensar en términos de fenómeno de masas, y no de simple literatura" (Corona, 2018, p. 11). Esto refleja el poder de los fans sobre la creadora ya que las decisiones de Rowling sobre la saga van dirigidas a controlar de alguna forma las creaciones transmedia de los fans sobre su propio universo, algunas de muy alta calidad como por ejemplo la película Voldemort: orígenes del heredero (2018) ${ }^{1}$. Este mediometraje fue realizado por la productora italiana independiente Tryangle gracias al mecenazgo de los fans. Tryangle fue denunciada por Warner Bros y J.K Rowling pero más tarde llegaron a un acuerdo en el que ambas partes dejaron claro que no podía existir ánimo de lucro permitiendo que el proyecto saliera a la luz de forma gratuita a través de Youtube.

Siguiendo esta misma trayectoria está la fanfilm Street Fighter: Assassin's Fist (2014) ${ }^{2}$ como ejemplo de adaptación al cine de un videojuego que supera con creces a las grandes producciones hollywoodienses en cuanto a fidelidad y respeto por el material original.

Otro ejemplo literario de intercambio de poderes lo vemos a través de la web Los siete reinos en la que los fans de la saga Canción de Hielo y Fuego de George R.R. Martin, más conocida como Juego de tronos. García-Roca expresa:

Manipulan los contenidos textuales para modificar y expandir la experiencia lúdica y estética $(. .$.$) el receptor se convierte en co-creador de la obra cuyas$ prácticas creativas en este medio poseen un potencial formativo extraordinario (...) en el ámbito de la educación literaria. (2016, p. 42) 
Siguiendo con Juego de Tronos, se ha podido ver recientemente otro ejemplo más del poder que pueden ejercer los fans. Tras el final de la serie basada en la obra de George R.R. Martin y producida por HBO, algunos de sus seguidores han comenzado una recogida de firmas "que tiene como objetivo que se reescriba toda la octava temporada para darle el final que se merece. La petición organizada a través de la plataforma Change.org, pide que se rehaga la octava temporada completa" (Prat, 2019 , p. 2-3). Aunque no es nada probable que esto suceda, el autor original de los libros ya está preparando varios Spin-off sobre el mismo universo. También es curioso destacar como los fans de los libros se han expresado con respecto al final de la serie y es que una de sus máximas alegrías es saber que el autor, a falta de publicar dos volúmenes para completar la historia, llevará por otros derroteros totalmente distintos el final de la misma.

Martin aseguró recientemente que ha modificado algunas partes para mantener a los lectores con la intriga, aunque hayan visto la serie. "Los puntos principales del final serán las cosas que ya dije hace cinco o seis años. Pero también puede haber cambios y habrá mucho que añadir" (Gilmore, 2014).

El uso de Internet y sus herramientas por parte de la comunidad activa y de los productores de contenido ha sufrido una evolución continua cuyos efectos son complejos de medir.

El uso primitivo de Internet y de las redes sociales por parte de las empresas productoras de contenido se destinaba al ámbito puramente publicitario y al marketing. Los primeros ejemplos de esto se pueden observar en las relaciones establecidas entre los fans de las películas o los videojuegos con las empresas autoras de contenido. Las compañías ponían en marcha la maquinaría publicitaria a través de la creación de webs oficiales muy rudimentarias e incluso experimentales dedicadas a la película o al videojuego que iban a estrenar. Estas webs suelen alojar contenido muy diverso sobre el producto: tráileres, galería de imágenes, entrevistas con los creadores, mini-juegos, concursos, etc. Este ejemplo se sigue practicando hoy en día pero ha quedado en segundo plano con respecto a otras técnicas de marketing.

Este modelo cerrado y vertical, presente incluso en los inicios de las redes sociales, se abre y evoluciona con la participación activa de los receptores y de esta manera las redes heredan en gran parte el funcionamiento de los blogs y otras plataformas de afiliación más obsoletas y aletargadas para acercarse de lleno y de una forma más personalizada al consumidor, el cual abandona su rol pasivo para dar visibilidad a sus opiniones, creaciones artísticas inspiradas en su película o videojuego favorito o 
simplemente poner un comentario en Youtube. Como señalan Aparici y Osuna, "la cultura de la participación implica modelos de comunicación horizontales donde las relaciones de poder proporcionan a cada individuo la posibilidad de intercambiar puntos de vista, expresar ideas, comentarios, experiencias así como trabajar colaborativamente" (2013, p. 137).

Independientemente del grado de participación, el sentimiento de pertenencia a una comunidad se hace cada vez mayor. Nace así la figura del pro-sumidor o co-autor, término acuñado por Alvin Toffler en su libro The third wave de 1980 e insinuado anteriormente por McLuhan (1972): "Con la tecnología electrónica el consumidor podría llegar a ser un productor al mismo tiempo" (p. 4).

En las últimas décadas, el videojuego ha sabido canalizar con éxito toda esta inercia artística y creativa acumulada durante años. Si bien existen ejemplos de fans artistas que crean sus pinturas o esculturas inspiradas en sus videojuegos favoritos y difunden su obra a través de las redes sociales, es el fenómeno del videojuego indie el que ha calado de forma rotunda todas las esferas y niveles de producción del entretenimiento electrónico.

El videojuego indie o independiente nace a principios de los 2000 pero no es hasta 2008 con la aparición de Braid, creado únicamente por Jonathan Blow, cuando este mercado crece progresiva y notablemente. Al contrario de lo que ocurre con las superproducciones o Triple $A$, los videojuegos independientes cuentan con poco presupuesto, suelen tener distribución digital y son realizados por equipos que en raras ocasiones sobrepasan los diez miembros. Braid "ostenta ese estatus de ser el indie que profirió el grito cuyo eco a día de hoy sigue resonando" (León y Delgado, 2019 , p. 50) y fue el que abrió la veda a otras producciones que, con el paso del tiempo, han conseguido acaparar una parte importante de la atención de los usuarios de videojuegos que buscan experiencias alejadas del mainstream y cercanas a las obras de autor como ocurre en el mundo cinematográfico.

Al no depender de los grandes estudios, los creativos ejercen un control total sobre el contenido de sus producciones y el resultado de ello son obras más personales que rezuman artisticidad. Muchos autores han comparado este fenómeno del videojuego independiente con la intencionalidad original de las vanguardias históricas de romper con las tendencias de la academia aunque si bien es cierto que, con el paso de lo moderno a lo posmoderno, la mayoría de videojuegos independientes actuales "niegan las genuinas intenciones vanguardistas" (Bürger, 2000, p. 115) y devuelven la obra al museo, al videojuego artístico a las esferas más comerciales, participando en una 
"restauración de la categoría de obra y en la aplicación con fines artísticos de los procedimientos que la vanguardia ideó con intención antiartística" (Bürger, 2000, pp. 113-114).

Bien es cierto que el panorama del videojuego independiente no se puede ejemplificar bajo lo dicho en el párrafo anterior puesto que las posibilidades actuales de este medio se presentan infinitas y difíciles de etiquetar. Desde las primeras producciones independientes, han surgido muchos proyectos que, si bien pretenden mantener intactas las intenciones originales del indie, se han desmarcado de ellos al ofrecer aparentemente lo mismo bajo otros modelos de negocio más ambiciosos como es el caso de Ori and the blind forest (Moon Studios, 2015), patrocinado enteramente por Microsoft, o Child of ligth (Ubisoft, 2014) entre otros muchos ejemplos.

Para reflejar de manera más contundente todo lo expuesto anteriormente, se ha procedido a la selección y breve análisis de algunos casos. Por un lado, la red social Assassin's Creed Council, dedicada únicamente a fans de esta popular saga de videojuegos $\mathrm{y}$, por otro, el videojuego independiente Blasphemous como caso ejemplar de proyecto nacido gracias al mecenazgo de los fans a través de los entornos digitales de participación.

Uno de los mayores inconvenientes a la hora de llevar a cabo esta investigación ha sido sin duda la selección de la muestra debido a la gran cantidad de ejemplos que existen para explicar la evolución y el panorama actual del videojuego y otras creaciones artísticas en relación con los entornos digitales de colaboración y la constante transformación que se produce en estos hábitats de infinitas e imprevisibles posibilidades. Por ello se ha intentado limitar la muestra a dichos casos para que este trabajo pueda servir como punto de partida a otros investigadores que quieran seguir desarrollándolo ya que, en este contexto, todos los casos en mayor o menor medida destacan por sus singularidades.

\section{RESULTADOS DE LA INVESTIGACIÓN}

\subsection{Interactividad bidireccional: del consumidor al prosumidor en los entornos digitales de colaboración}

Llegados a esta parte de la investigación, se procede a analizar de manera breve algunos casos significativos en el ámbito de las redes sociales dedicadas a los videojuegos así como algunos ejemplos de videojuegos independientes nacidos de proyectos llevados a cabo por fans a través del crowdfunding. 
El videojuego, debido en parte a su naturaleza, se ha mostrado permeable a todos los procesos descritos lo que ha conllevado la rápida expansión del modelo horizontal de producción dentro de una "cultura participativa más amplia, que incluye todo aquello que va más allá de la pantalla, del propio acto de jugar" (Muriel, 2016, p. 7). En Playing with videogames, Newman (2008) proporciona algunas claves sobre las herramientas que amplían la experiencia de jugar a videojuegos: guías paso a paso creadas por y para fans para superar los obstáculos del videojuego, mods, fan arts, reseñas, cosplay y mucho más. Como afirma Crawford (2012), "jugar a videojuegos es mucho más que la simple interacción de uno o varios individuos con una máquina de videojuegos" ( $p$. 120). No sólo de trata de jugar a videojuegos sino de expandir las prácticas relacionadas más allá de sus posibilidades básicas.

Este papel del videojuego en la cultura de la convergencia y su rol de agentes dinámicos permite construir entornos digitales basados en la colaboración y participación ofreciendo potentes oportunidades de comunicación y producción creativa (Cortés, García y Lacasa, 2012, p. 2).

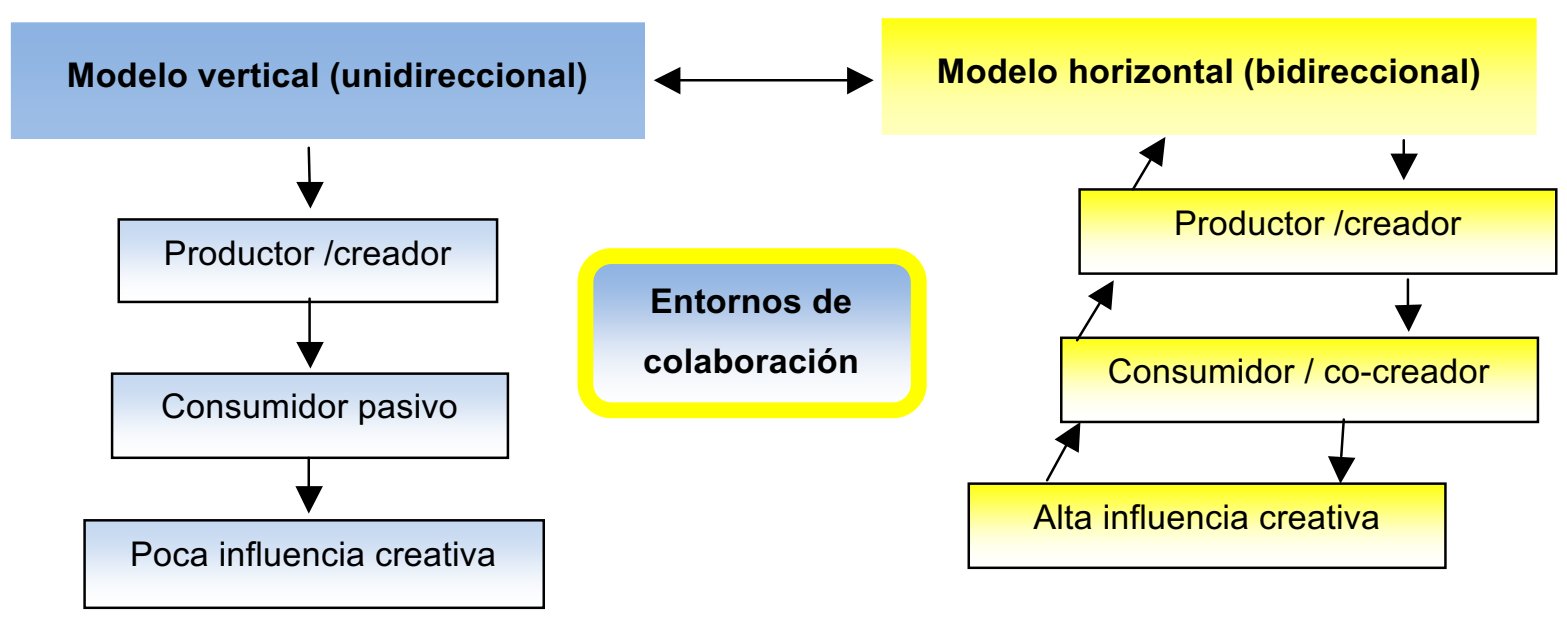

Figura 2. Del modelo vertical al horizontal en la convergencia digital.

Fuente: elaboración propia.

\subsection{Las redes sociales por y para fans de videojuegos}

La actividad del usuario de videojuegos se ve fomentada por dos características principales que se retroalimentan entre sí: de una parte, por el sentido propio e implícito de comunidad, potenciado a su vez por la expansión de Internet y del juego 
online y, por otro lado, por la absorción de la jerarquía, estructura y funcionamiento de las redes sociales por parte de las plataformas usadas por estas comunidades.

El videojuego online ofrece también una plataforma de colaboración compleja en la que se comparten diversos tipos de contenidos. Como ejemplo pionero en este sentido se presentó en 2008 Little Big Planet, un videojuego de plataformas y lógica desarrollado por Media Molecule para Playstation 3. Fue un primer intento serio de crear una comunidad de jugadores/creadores en el mercado de las consolas de sobremesa. El jugador de Little Big Planet puede, mediante una potente herramienta de edición, diseñar libremente los escenarios y compartirlos online con otros jugadores como reza el eslogan del juego: "juega, crea, comparte".

Se podría decir que las plataformas digitales de convergencia entre jugadores de videojuegos son principalmente de dos tipos: las creadas por los fans para fans y las creadas por las compañías de videojuegos para los fans con fines sobretodo publicitarios. Ambas son caldo de cultivo para las creaciones artísticas y claras herederas de las funcionalidades de las redes sociales.

Las redes sociales o plataformas creadas por la empresa, a pesar de que poseen opciones gratuitas, suelen tener un carácter más cerrado y ofrecen servicios de pago para el jugador. Estas prestaciones suelen incluir descarga de juegos gratuitos, juego online y guardado de datos en la nube, entre otros. Cada empresa posee su comunidad de jugadores. Las más actuales son:

- Xbox live ${ }^{3}$ (2002): es la plataforma de Microsoft que presta servicios y da soporte a la comunidad de la consola Xbox One. Ofrecen posibilidad de juego online y streaming o descarga de una selección de videojuegos a cambio de una cuota mensual. También tiene servicio de mensajería y chat de voz entre usuarios. Cabe destacar que esta plataforma fue una de las primeras en distribuir videojuegos independientes realizados por aficionados.

- Playstation Network ${ }^{4}$ (2006): es la plataforma de Sony ofrecida a los poseedores de una consola Playstation 3 ó 4 . Los servicios son similares a los de Microsoft pero esta plataforma es más limitada en cuanto al crossplay o juego cruzado, es decir, los jugadores del mismo juego en sistemas diferentes de consolas o pc no se mezclan en las partidas online.

- Nintendo Switch Online ${ }^{5}$ (2017): ofrece partidas online a sus jugadores a través de su consola de sobremesa actual. 
Por otro lado, existen las redes sociales albergadas en sitios web que son creadas por fans y consumidores activos para la participación de fans. Algunos ejemplos de este tipo son:

- Rol con dados ${ }^{6}$ : se trata de una comunidad de jugadores de rol tanto de tablero como online. Aquí los jugadores crean sus propias estadísticas sobre sus partidas para competir entre sí y contactan con jugadores de gustos afines.

- Uberchar?: es una red muy grande que mantiene conectado a todos los jugadores de los videojuegos online multijugador o Massively Multiplayer Online (MMO).

- Second Life: más que una red social es un simulador de vida social. Permite crear una identidad y jugar sin límites. Tiene moneda propia dentro de la red y cualquier idea se puede llevar a cabo, desde un proyecto empresarial pequeño hasta una campaña masiva de product placement.

- Nosplay8: es quizá la red de videojugadores más grande y popular del panorama español y latino. Los usuarios pueden compartir videos de sus partidas, opiniones, reseñas y cualquier tipo de contenido relacionado con los videojuegos. Su enorme éxito radica en que está abierta a todo tipo de seguidores sin restricciones a ningún género o estilo de videojuegos.

\subsubsection{Assassin's Creed Council}

El caso de la red social Assassin's Creed Council ${ }^{9}$ es un referente a tener muy en cuenta dentro de esta clase de fenómenos de la cultura participativa en los videojuegos. Fundada por la franco-canadiense Ubisoft en 2015, creadora de la exitosa saga de videojuegos de corte histórico Assassin's Creed (2007-2018), supone un ejemplo por antonomasia de la creación de contenidos artísticos por parte de los consumidores activos, cuya única limitación supone crear contenido inspirado en esta franquicia de videojuegos todo ello ambientado en el universo de la saga.

En la página de inicio, el usuario tiene la posibilidad de moverse por una barra de navegación de estilo clásico. Bajo esta barra se puede leer en mayúsculas: "Hazte miembro" junto al botón de suscripción. Si se pulsa en la suscripción, el usuario puede leer las reglas y funciones principales ofrecidas por la red:

Querido futuro Asesino: estás a solo un paso de unirte al Consejo de Assassin's Creed. Necesitas una cuenta Uplay para poder acceder a las características del Consejo de Assassin's Creed.

- Crea contenido, comparte, reacciona y puntúa los mensajes de otros Asesinos 
- Recibe puntos como premios e insignias especiales para subir en los rangos de Asesinos

- Marca la diferencia con tu opinión. (Ubisoft, 2015)

En la barra de navegación están los botones de "comunidad", "estudio", "clasificación", "insignia y puntos" y "acerca de The Council". La mayoría de acciones a realizar en la red, desde compartir un enlace de un video a comentar una aportación de otro usuario, requiere un registro y una creación de perfil. Estas características sistemáticas se basan literalmente en el funcionamiento de otras redes masivas como Youtube o Facebook.

En el apartado "acerca de" se ofrece el enlace a un vídeo explicativo en el que se muestra con un tono publicitario muy marcado las ventajas de suscribirse a esta comunidad. También se resumen por escrito las funciones más destacadas para el usuario:

En The Council podrás conseguir información oficial e inmediata de los productores del juego (...) también puedes transmitir al estudio tus preferencias y expresar toda tu creatividad si votas y participas en los desafíos (...) publica contenido o comentarios, también tienes poder sobre el contenido de otros contribuidores al votar y compartir (...) envía tus logros a la comunidad y aumenta tu influencia: tu participación y prestigio serán recompensados mediante un sistema de puntos e insignias (Ubisoft, 2015).

En esta red existe una jerarquía entre los miembros afiliados, los cuales van mejorando su reputación y abanico de acciones dentro de "la Hermandad de los Assassin's" gracias a los puntos que van obteniendo dependiendo del grado de implicación en sus creaciones y aportaciones. Desde foros de debate hasta concursos de dibujo o de cortos de cine inspirados en el universo de Assassin's Creed. También se ofrecen entrevistas con los creadores de los videojuegos, los cuáles se han mostrado siempre con una actitud abierta ante las peticiones de los fans a incluir en futuras entregas. Es una demostración más de que los usuarios obtienen cierto poder e influencia sobre las decisiones de las empresas creadoras.

Por contrapartida, y aunque los usuarios se animen a inscribirse por el añadido de ser un creación o producto oficial, el hecho es que esta red social pertenece a la empresa Ubisoft y todo el contenido publicado está controlado y limitado creando así un efecto ilusorio de participación que limita y dirige las acciones de los participantes. A pesar de esto, se trata de un ejemplo paradigmático dentro los entornos digitales de 
participación porque evoca y transmite al usuario la capacidad o ilusión de poder con la posibilidad de expandir el universo del juego y alterar los modelos relacionales clásicos entre autor - creador y usuario - consumidor. Este modelo, como se ha visto en ejemplos anteriores, se da también en otras redes creadas por fans en las que las funciones son similares pero sin las limitaciones expuestas.

Estas redes se basan principalmente en el fenómeno anticipado por Jenkins muchos años antes según el cual el fan adquiere una relevancia notable al poder opinar y participar de forma activa sobre las creaciones que admira en un universo transmedia convirtiéndose en muchos casos en agentes generadores de contenido artístico inspirado por dichas creaciones. Aunque este tipo de redes está cayendo en desuso por su gran parecido a las redes clásicas, es palpable el eco que han propiciado en otros entornos digitales de colaboración más avanzados que completan, expanden y potencian las posibilidades de un ecosistema cultural digital que ya era complejo en sus inicios.

\subsection{Usos y repercusiones de las plataformas de creación y difusión de contenido}

Plataformas web de publicación gratuita de videos como Youtube, activa desde 2005, han demostrado el potencial y las consecuencias de las relaciones horizontales entre autores y consumidores activos. Burguess y Green (2009) señalan que

Youtube also presents us with an opportunity to confront some of participatory culture's most pressing problems: the unevennes of participation and voice; the apparent tensions between comercial interests and the public good; and the contestation of ethics and social norms that occurs as belief systems, interests, and cultural differences collidle (p. 8).

A pesar de que existe una sinergia y un feedback constante entre todos los usuarios de Youtube y que todos los consumidores de contenido participan en el sentimiento de pertenencia, coexiste una brecha muy grande entre los consumidores pasivos. Por un lado están los usuarios que dedican su tiempo en la plataforma a visualizar los videos de los creadores de contenido (tanto de Youtubers grandes como de empresas productoras de contenido musical, por ejemplo) y, por otra parte, están los creadores activos de contenido los cuales acumulan seguidores y visualizaciones en sus videos (sistema por el cual se calcula la monetización de los videos compartidos). Estos últimos son los verdaderos impulsores de Youtube y los que hacen honor a su eslogan. Nace así la figura del Youtuber. Un "oficio" que se pueden permitir sólo los 
que tienen millones de seguidores que visualizan sus videos suponiendo así una monetización rentable.

Cada usuario puede optar, a través de la creación de canales, por implicarse más o menos en la aportación de contenido. Con el paso de los años, la plataforma se ha convertido en un reflejo de la sociedad ya que, si se profundiza en el concepto de forma metafórica, Youtube sería como un almacén cultural en constante evolución con los usuarios en el que el único límite lo ponen los términos y condiciones impuestos por Google.

La plataforma alberga contenido relacionado con los videojuegos prácticamente desde sus inicios. Aquí se vuelve a repetir el mismo modelo horizontal de comunicación entre las empresas poseedoras de un canal en Youtube y los usuarios que exponen sus opiniones, reseñas y videos sobre diversos temas relacionados con los videojuegos. Sin embargo, los creadores tienen aquí una influencia mucho mayor y más directa sobre el resto de usuarios ya que, si consiguen un gran número de seguidores, sus videos ganan en visibilidad rápidamente quedando así expuestos a millones de personas en todo el mundo.

Los contenidos sobre videojuegos, si bien son de temáticas prácticamente ilimitadas, se centran en unas fórmulas que siguen las tendencias impuestas por los videocreadores y por las exigencias de los usuarios. Son numerosos los canales de videojuegos que tratan únicamente de gameplays, es decir, en el vídeo se muestra el Youtuber de turno jugando y comentando videojuegos antiguos y/o actuales. La plataforma Twitch, propiedad de Amazon, está dedicada en exclusiva a esta función. Existen también video-reseñas, video-reflexiones, video-reacciones, cortos cinematográficos inspirados en videojuegos, tutoriales, guías paso a paso, etc.

Los contenidos de los usuarios, en el caso de los canales grandes, suelen extrapolarse a otro tipo de actividades fuera de la plataforma. Algunos Youtubers dedicados a contenidos sobre videojuegos han conseguido publicar libros, ofrecer merchandising basado en su propia marca (generalmente a través de acuerdos con otras marcas fabricantes o sponsors) o incluso logran que grandes empresas los contraten para diversas actividades a desarrollar dentro o fuera de la plataforma.

\subsection{La plataforma Kickstarter y Blasphemous}

Mención aparte merece el sitio online basado en el crowdfunding Kickstarter. Activo desde 2009, y según sus estadísticas, 16 millones de personas han contribuido con 
4,3 miles de millones de dólares a la realización de 164.297 proyectos (cifra a día 0306-2019).

A pesar de que se basa en una idea muy sencilla, la fórmula de micro mecenazgo ha favorecido que millones de personas en todo el mundo compartan sus proyectos creativos y los saquen a la luz. La iniciativa recoge proyectos relacionados con el arte, los comics, la ilustración, cine, juegos, publicaciones y tecnologías. Los usuarios pueden emprender sus proyectos de forma libre y autónoma para promover la captación de recursos económicos con solo registrar su idea en la web.

Algunos de los proyectos más exitosos dentro de la plataforma son los videojuegos. Uno de los ejemplos actuales más notables es el caso del creador japonés Yu Suzuki y la tercera parte de la saga Shenmue ${ }^{10}$. Este proyecto salió adelante rápidamente debido en gran parte a que el programador ya era conocido por haber creado las dos primeras entregas para sistemas populares de consolas de sobremesa. Yu Suzuki triplicó en cuestión de horas la cantidad inicial para hacer posible el proyecto, una suma que ha alcanzado 6.333.295 dólares provenientes de casi 70.000 patrocinadores. El juego se pondrá finalmente a la venta en agosto de 2019.

Uno de los casos ejemplares de videojuegos patrocinados gracias a Kickstarter, tiene origen en una pequeña productora independiente con base en Sevilla. The game kitchen, un estudio formado originalmente por cuatro personas que recaudó 5.000 euros para su primer proyecto The last door, un videojuego con estética pixel art basado en relatos de Edgar Allan Poe.

Para su segundo proyecto, estos creativos se pusieron como meta recaudar 50.000 dólares, cifra que han superado notablemente con 333.246 dólares. Nace así Blasphemous $^{11}$, un videojuego independiente de acción en scroll lateral $2 \mathrm{D}$ y de estética pixel art ambientado en la Semana Santa andaluza y que tiene como protagonista a un guerrero-nazareno armado con una espada para enfrentarse a los enemigos que le salen al paso durante su recorrido por escenarios inspirados en títulos como Castlevania Symphony of the night (1997).

El videojuego aún está en desarrollo debido a que sus creadores han ido dotando de calidad y posibilidades al mismo conforme aumentaba el dinero recaudado. Su fecha de lanzamiento aún se desconoce pero según las últimas declaraciones de los creadores debe estar muy próxima. En la web oficial ${ }^{12}$ del juego ya están disponibles algunas capturas de pantalla y diseños que dejan entrever el aspecto que tendrá. 
Kickstarter supone un punto de inflexión dentro de los modelos de cultura participativa a gran escala así como una vuelta de tuerca más en los arquetipos del fan o usuario como creador de contenidos y Blasphemous es solo un ejemplo entre cientos de videojuegos independientes que están emergiendo gracias a este tipo de prácticas comerciales. Con el ejemplo de este pequeño estudio y su obra se pueden denotar los profundos cambios que están teniendo lugar en las esferas de la producción cultural en general y del arte digital en particular.

Blasphemous comparte con otros videojuegos independientes que sobresalen por su artisticidad como Limbo (2010), Gris (2018) o Rime (2017), todos de manufactura española, algunas características como la distribución digital, la autofinanciación o la financiación por mecenazgo. Factores que, una vez más, han ayudado a subvertir la clásica relación entre autores y usuarios. De hecho, los creadores de Blasphemous son usuarios de videojuegos desde la infancia lo que ofrece un panorama alentador para otros artistas en potencia que participan de esa comunidad o que provengan de otras disciplinas artísticas.

Se demuestra con esto que en el respeto por el material original o de referencia reside el poder y el buen gusto de estas producciones independientes surgidas casi del anonimato.

\section{DISCUSIÓN Y CONCLUSIONES}

Los modelos de convergencia digital analizados en la investigación se encuentran en constante evolución, de ahí la dificultad de su estudio a la hora de seleccionar una muestra representativa que arroje luz sobre las cuestiones planteadas.

Casos como los mostrados anteriormente vienen a resaltar solo algunos de los cambios más trascendentales que están teniendo lugar dentro de los entornos digitales de colaboración.

Antes de la llegada de Internet y las webs de libre creación de contenido, un escritor tenía que llevar su manuscrito a distintas editoriales para que, con suerte, le publicaran la obra. En la actualidad, esas prácticas están cayendo en desuso gracias a que existen medios digitales a través de los cuales auto-publicar los proyectos o ayudar a su financiación y, como se ha visto, este ejemplo es extrapolable a empresas de diversa índole.

Por otro lado, el rol clásico de la gran compañía productora y distribuidora de contenidos culturales y artísticos se ha difuminado en un panorama de comunicación 
horizontal en el que la figura del usuario activo va ganando terreno. Esto, a corto y a largo plazo, supone un cambio de estrategia constante para las grandes empresas, ya que el éxito comercial pasa por mantener el control sobre los modelos de negocio.

En la actualidad, los usuarios de videojuegos forman una comunidad que ramifica sus posibilidades creativas en múltiples esferas de la convergencia digital lo que, sin lugar a dudas, les confiere un poder inédito dentro de la industria cultural y del entretenimiento.

Este potencial puede servir de catalizador para plantear propuestas innovadoras en todos los ámbitos culturales. El camino de futuras investigaciones dentro de los estudios sobre videojuegos y cultura participativa se presenta incierto. Esto es así debido a que es complicado intentar vaticinar cuáles serán las tendencias en un entorno tan complejo y cambiante como el analizado.

El uso de Internet, las redes sociales y todas las herramientas digitales permiten conectar de alguna forma los intereses culturales de toda una población posibilitando que las sociedades actuales encuentren así la inercia necesaria para evolucionar.

La tara principal de los estudios culturales basados en los entornos participativos digitales se hace patente en la crítica de Couldry a Jenkins. En la era digital no todos los usuarios tienen las mismas capacidades tecnológicas ni culturales. Quizá el futuro de estas investigaciones pase por analizar los casos de pueblos y culturas que se vayan sumando a las prácticas que, a ojos de los países del primer mundo, parecen tan sistematizadas.

\section{Notas}

1. Véase: https://www.youtube.com/watch?v=qWOHJmxw5L0 (consultada el 2/06 de 2019).

2. Véase: https://www.youtube.com/watch?v=fzBtAO6F8fk (consultada el 2/06 de 2019).

3. Página web de la plataforma Xbox-Live disponible en https://www.xbox.com/es-ES/live (consultada entre el 5/11 y el 22/11 de 2018).

4. Página web de la plataforma oficial de Sony para Playstation disponible en https://store.playstation.com/es-es/home/games (consultada entre el 5/11 y el 22/11 de 2018).

5. Página web oficial de Nintendo disponible en https://www.nintendo.es/ (consultada entre el $5 / 11$ y el 22/11 de 2018). 
6. Sitio web de la red social "Rol con dados" disponible en https://rolcondados.com/ (consultada entre el 5/11 y el 22/11 de 2018).

7. Sitio web de la red social "Uberchar" disponible en http://www.uberchar.com/ (consultada entre el 5/11 y el 22/11 de 2018).

8. Sitio web de la red social "Nosplay" disponible en http://www.nosplay.com/ (consultada entre el $5 / 11$ y el $22 / 11$ de 2018 ).

9. Sitio web de la red social "Assassin's Creed Council" disponible en https://council.assassinscreed.com/es/ (consultada entre el 5/11 de 2018 y el 2/06 de 2019). Tráiler de lanzamiento de la red social en: https://www.youtube.com/watch?time_continue=4\&v=o8E9w4hQg4s

10. Sitio web del proyecto de Kickstarter de Shenmue 3 disponible en https://www.kickstarter.com/projects/ysnet/shenmue-3/description (consultado el 28/1/2019).

11. Sitio web del proyecto de Kickstarter de Blasphemous disponible en https://www.kickstarter.com/projects/828401966/blasphemous-dark-and-brutal-2d-non-linearplatform?lang=es (consultado el 28/1/2019).

12. Véase web oficial del videojuego Blasphemous disponible en http://blasphemousgame.com/ (consultado el 28/1/2019).

\section{Referencias}

Aparici, R. y Osuna Acedo, S. (2013). La Cultura de la Participación. Revista Mediterránea de Comunicación, vol. 4 (2), 137-148. doi:10.14198/MEDCOM2013.4.2.07

Bürger, P. (2000). Teoría de la vanguardia. Barcelona: Península.

Burguess, J. y Green, J. (2009). Youtube: Digital Media and Society Serie. Cambridge: Polity Press.

Corona, A. (2018). J.K. Rowling contra el fandom: cómo el universo de Harry Potter perdió la magia. Xataca cine y televisión. Recuperado de https://www.xataka.com/cine-y-tv/j-krowling-fandom-como-universo-harry-potter-perdio-magia

Cortés Gómez, S.; García Pernía, M.R. \& Lacasa, P. (2012). Videojuegos y redes sociales. El proceso de identidad en Los Sims 3. RED, Revista de Educación a Distancia, 33, 1-18.

Couldry, N. (2011). More sociology, more culture, more politics: or, a modest proposal for 'convergence' studies. Cultural studies, 25 (4-5), 487-501.

Crawford, G. (2012). Video Gamers. London: Routledge. 
García-Roca, A. (2016). Prácticas lectoras en espacios de afinidad: formas participativas en la cultura digital. Ocnos. Revista de estudios sobre literatura, 15, 42-51.

Gilmore, M. (2014). George R.R. Martin: The Rolling Stone interview. Recuperado de https://www.rollingstone.com/culture/culture-news/george-r-r-martin-the-rolling-stoneinterview-242487/

Jenkins, H., Clinton K., Purushotma, R., Robinson, A. y Weigel, M. (2009). Confronting the Challengues of Participatory Culture: Media Education for the 21st Century. Cambridge, MacArthur Foundation: the MIT Press.

Jenkins, H. (2006). Convergence Culture: Where old and new media collide. New York: NY University Press.

Jenkins, H. (1992). Textual Poachers, televisión fans and participatory culture. Massachussets: Routledge.

León, J. y Delgado, M. (2019). Revolución indie: la subversión cultural del videojuego. Sevilla: héroes de papel.

Manzur, K. (2017). Creando comunidad a través de los videojuegos en red: reinventando los juegos sociales (tesis doctoral). Madrid: Universidad de Alcalá.

Mcluhan, M. y Barrington, N. (1972). Take Today. The executive as dropout. Canadá: Brace Jovanovich.

Muriel, D. (2016). Cultura participativa y videojuegos [entrada en blog]. Recuperado de http://www.zehngames.com/thinkpieces/cultura-participativa-videojuegos/

Newman, J. (2008). Playing with videogames. London: Routledge.

Prat, J.P. (2019). Indignados. Fans recogen firmas para rehacer la octava temporada de Juego de Tronos. Recuperado de https://www.zonared.com/tv/fans-recogen-firmas-rehaceroctava-temporada-juego-de-tronos/

Ubisoft (2015). Assassin's Creed Council (red social oficial). Recuperado de https://council.assassinscreed.com/es/ 